\title{
Proposta lexicográfica para verbetes de dicionário especial de homônimos da Língua Brasileira de Sinais - Libras
}

DOI: http://dx.doi.org/10.21165/el.v49i2.2570

\section{Érika Lourrane Leôncio'}

\section{Resumo}

Apoiados em Haensh (1982), Biderman (1978, 1984, 1992); Carballo (2003), Ullmann (1964), Liddell e Johnson (1989), Faria-do-Nascimento (2009), desenvolvemos uma proposta de verbete para o registro, em dicionário especial, de itens lexicais homonímicos da Língua Brasileira de Sinais - Libras. Nosso propósito foi desenvolver um modelo de verbete capaz de registrar e sistematizar a ocorrência da homonímia e seus usos na libras. Para exemplificar o modelo, apresentamos, neste artigo, cinco verbetes para as formas homônimas dos sinais SÁBADO, MÃE, MINUTO, DIREITO, BAHIA. Na proposta, optamos pela ordenação semasiológica, baseada no princípio de ordenação paramétrica, as informações selecionadas para o Programa Constante de Informações (PCI) foram as de ordem: (i) gramatical (classificação gramatical); (ii) semântica (definição, sinônimos); (iii) sintática (exemplos de uso) e (iv) pragmáticas (área do conhecimento, regionalismo).

Palavras-chave: léxico homônimo da libras; dicionário especial; verbete.

1 Instituto Federal de Educação, Ciências e Tecnologia (IFPI), Nova Corrente, Piauí, Brasil; erika.lourrane@ifpi.edu.br; https://orcid.org/0000-0002-7802-9087 


\title{
Lexicographic proposal for entries in the special dictionary of homonyms of the Brazilian Sign Language - Libras
}

\begin{abstract}
Supported by Haensh (1982), Biderman (1978; 1984; 1992); Carballo (2003), Ullmann (1964), Liddell \& Johnson (1989), Faria-do-Nascimento (2009), we developed a proposal for the entry, in a special dictionary, of homonymic lexical items of the Brazilian Sign Language - Libras . Our purpose was to develop an entry model capable of recording and systematizing the occurrences of homonym and its uses in libras. In all, five entries were systematized for the homonymous forms of the signs SATURDAY, MOTHER, MINUTE, RIGHT, BAHIA. In the proposal, we chose the semasiological ordering, based on the principle of parametric ordering, the information selected for the Constant Information Program (PCl) were of the order: (i). grammatical (grammatical classification); (ii). semantics (definition, synonyms); (iii). syntactic (examples of use) and (iv). pragmatic areas (knowledge area, regionalism).
\end{abstract}

Keywords: libras namesake lexicon; special dictionary; entry.

\section{Considerações iniciais}

O estudo da homonímia da libras poucas vezes foi objeto de estudo de linguistas. No Brasil, os estudos mais profícuos foram os de Soares (2013) e Martins (2013). Os sinais homônimos da libras ainda não gozam de registro sistemático em dicionários da língua, seja de tipologia geral ou especial. Por isso, informações como essas não são acessíveis aos usuários em geral. Logo, este artigo² ${ }^{2}$ cuja base teórica faz interface entre a Lexicologia, a Lexicografia e a Metalexicografia, propõe elaborar discussões na área para tentar preencher lacunas, como as apontadas acima. Nesse sentido, este trabalho apresenta um modelo de verbete específico para o registro da homonímia da libras em dicionário do tipo Especial, voltado para o público de tradutores/intérpretes de Libras/LP, professores bilíngues da disciplina de Libras como L1 (primeira língua) do surdo, surdos bilíngues L1-L2 (segunda língua), e, também, profissionais ou membros da comunidade surda que trabalham com essa língua nas áreas de Arte, Literatura, Comunicação Jornalística ou Midiática.

Ao longo do trabalho, referências importantes da Lexicografia e da Semântica Lexical (com foco na homonímia da Língua Portuguesa, doravante LP, e da Língua de Sinais, doravante LS), como Haensch (1982), Biderman (1978, 1984, 1992); Carballo (2003),

2 Resultado parcial da pesquisa de Mestrado intitulada "Proposta lexicográfica para verbetes de dicionário especial de homônimos da Língua Brasileira de Sinais - Libras", desenvolvida no Programa de Pós-graduação em Letras da Universidade Federal do Piauí - UFPI. 
Ullmann (1964), Faria-do-Nascimento (2009) e Soares (2013), trouxeram tessitura às discussões.

\section{A homonímia e o seu registro em dicionários}

É comum que as palavras nas línguas faladas, assim como os sinais nas línguas gestuaisvisuais, apresentem mais de um significado, com duas ou mais significações diferentes. Apesar de contribuir para a economia e flexibilidade da língua, essa propriedade semânticoarticulatória gera ambiguidades de ordem fonética, gramatical e lexical (ULLMANN, 1964). A ambiguidade de ordem lexical, sobre a qual tratamos neste artigo, pode ser gerada de três formas: pela homonímia, polissemia ou categorização gramatical.

A homonímia ocorre quando os sentidos são completamente distintos ou não se relacionam; a polissemia, quando uma palavra pode designar múltiplos significados com semas em comum; e a categorização gramatical, quando uma mesma unidade lexical pertence a classes sintáticas distintas. Basicamente, a diferença entre as duas primeiras está nas relações que as palavras ambíguas têm ou não entre si (CANÇADO, 2008).

Os estudos semânticos mais tradicionais apontam que a homonímia se apresenta de duas maneiras: nas formas homófonas (mesmo som e com grafia diferente) e homógrafas (mesma grafia e com som diferente). Apesar de haver essa divisão, Cançado (2008), assim como Ullmann (1964), não considera relevante essa bipartição, já que a diferença na grafia por si só não é conclusiva para a identificação da homonímia. Para as Línguas de Sinais - LSs, essa divisão também não é produtiva, já que elas ainda não possuem uma representação escrita universal legítima, aceita oficialmente, apesar das tentativas mais recentes de Valerie Sutton com o sistema SignWriting (escrita de sinais) (Cf. SUTTON, 2019 [1974]).

A fim de ilustrar a homonímia da LS, criamos, com base em Baldinger (1970), o diagrama ilustrado com sinais, representado logo abaixo:

Figura 1. Homonímia na Língua de Sinais

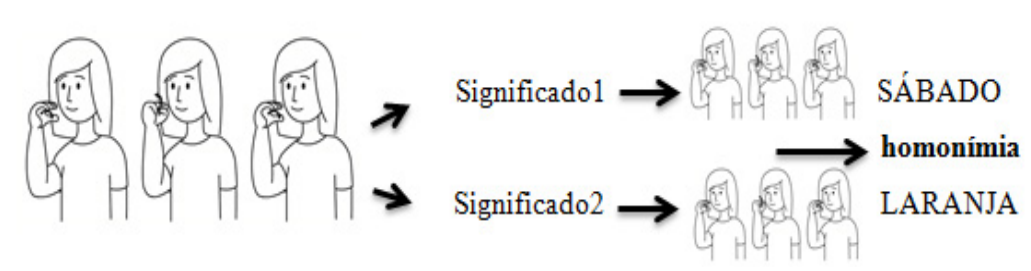

Fonte: Elaboração própria 
Conforme Biderman (1978), é possível encontrar até três tipos de homônimos, a saber: o homônimo léxico (pertencente à mesma classe sintática, com significados diferentes); o sintático (pertencente a classes sintáticas diferentes); e o morfológico (incluído na mesma classe sintática com categorias gramaticais diversas).

Na língua portuguesa, um caso clássico de homônimo léxico são as lexias banco (substantivo), banco (substantivo); e na libras, os sinais MÃE (substantivo) e BISCOITO (substantivo) (ver ilustração a seguir):

Figura 2. Homônimos: MÃE e BISCOITO

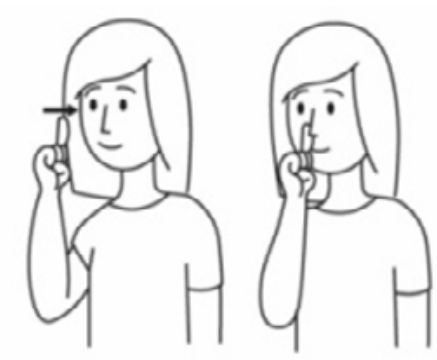

MÃE (variação do RS e SC)

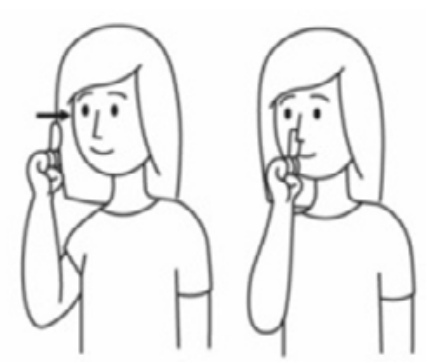

BISCOITO

Fonte: Elaboração própria

Glosa3: MAMÃE IMPORTANTEmuit@ EL@ SEMPRE PREOCUPAR CUIDAR FILH@ (FELIPE; LIRA, 2005).

Tradução: A mãe é muito importante. Ela está sempre preocupada e cuidando do filho.

Glosa: BISCOITO BANANA VOCÊ JÁ COMER? (FELIPE; LIRA, 2005).

Tradução: Você já comeu biscoito de banana?

Quanto aos homônimos sintáticos, as unidades caminho (substantivo) e caminho (verbo) ilustram um exemplo do português, e os sinais BAHIA (substantivo) e SENTIR (verbo), um exemplo da libras:

3 Conforme Felipe (2014), "glosas" é um sistema de representação semântico-discursiva do sinal. Trata-se de uma convenção para representar os sinais da Libras por meio de palavras, sinais gráficos e tipográficos. Nesta pesquisa foi adotado o "Sistema de Transcrição em Palavra" (FELIPE, 1988, 1998). 
Figura 3. Homônimos: BAHIA e SENTIR

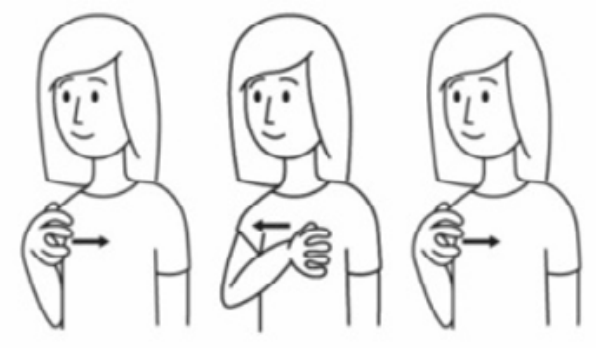

BAHIA

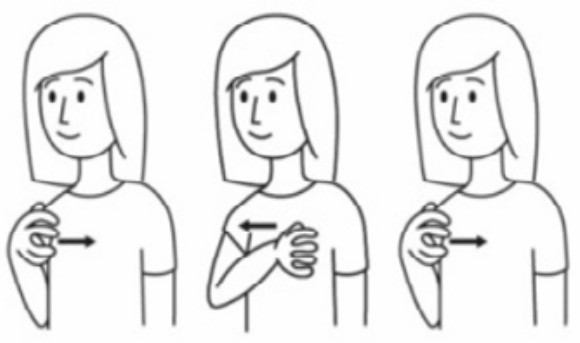

SENTIR

Fonte: Elaboração própria

Glosa: CARNAVAL EU IR JÁ BAHIA (FELIPE; LIRA, 2005).

Tradução: EU já fui ao carnaval da Bahia.

Glosa: HOJE EU SENTIR BEM NÃO (FELIPE; LIRA, 2005).

Tradução: Hoje eu não me senti bem.

Como exemplo de homônimo morfológico, Biderman (1984) citou as formas verbais amamos, tanto na forma do presente do indicativo como no pretérito perfeito: "nós amamos" (verbo no presente do indicativo); "nós amamos" (verbo no pretérito perfeito). $\mathrm{Na}$ língua de sinais, exemplos semelhantes não podem ser vistos nos casos em que os verbos não sofrem flexões de tempo e de gênero direto na forma lexical (QUADROS; KARNOPP, 2004). No caso dos verbos que sofrem flexão de número-pessoa, largamente estudados por Felipe $(1988,1997,1998)$, pode ser citado como exemplo o sinal NÓS DOIS PASSAMOS (verbo no presente do indicativo) e NÓS DOIS PASSAMOS (verbo no pretérito perfeito).

Soares (2013) também utilizou uma classificação parecida com a de Biderman (1978) ao mencionar que as homonímias da LS poderiam se apresentar na forma perfeita e imperfeita. Para o autor, o primeiro tipo é aquele com mesma classe gramatical e total convergência paramétrica; e o segundo aquela com classe gramatical e expressões nãomanuais (ENMs) diferentes. 
Soares (2013) mencionou como homonímias perfeitas, dentre outras, os pares4: FAZENDA (SP, MG, PR, RS)/BOI (SP, RJ, DF, SC, AL, BA, MG, CE, RS, PR); ADOTAR (CE, RJ)/ LUCRAR (PE) ${ }^{5}$; RESPEITAR (SP, RJ, MG, MS, CE, RS, PR, SC, DF)/OBEDECER (SP, RJ, MS, $P R, M G, A L, C E, S C, R S)$. Conforme o autor (2013), esses sinais não diferem em nenhum parâmetro, uma vez que possuem os mesmos constituintes fonológicos e a mesma classe gramatical, ou seja, são dois verbos.

Já como imperfeitas, Soares (2013) citou o par: HISTÓRIA e LEMBRAR. Para ele (Ibidem, p. 112-113), "nos dois casos, o item lexical difere em parâmetros fonológicos em expressão não-manual (ENM), representando dessa forma homonímia imperfeita". O próprio contexto confirma tal distinção, como se vê na aplicação contextual fornecida pelo autor:

UAU PASSADO HISTÓRIA PASSADO UAU SURDO ENSINAR PROFESSOR SURDO. Tradução: Puxa, há muito tempo na história um surdo professor ensinou [...]. (SOARES, 2013, p. 113, grifo nosso).

LEMBRAR O QUE BARREIRA COMUNICAÇÃO POR CAUSA ENTRAR SOCIEDADE ISTO $<$ DIFICIL, FÁCIL>Sn NÃO. Tradução: Me lembro, minha comunicação na sociedade não foi fácil. (SORARES, 2013, p. 114, grifo nosso).

Além das homonímias imperfeitas acima, encontramos também os sinais, AGOSTO/ GOSTAR, SEXTA-FEIRA/PEIXE, DIRIGIR/CARRO, AVIÃO/VOAR DE AVIÃO, ABRAÇO/ ABRAÇAR, AÇÚCAR/DOCE, dentre outros.

É importante salientar, no entanto, que os sinais homônimos da Libras ainda não gozam de registro sistemático em dicionários da língua. Nesse sentido, a fim de ilustrar o tratamento da homonímia em dicionários gerais e especiais da LP, esboçamos, no subitem a seguir, alguns exemplos, com análises e conceituações da macro e micro estrutura, à luz de importantes nomes da Lexicografia.

\section{Macro e microestrutura: questões teóricas e o tratamento da homonímia em dicionários}

A microestrutura é o elemento do dicionário que guarda as informações individuais da entrada. Ela se divide em partes menores, segundo propostas variadas. Barbosa (1996,

40 escopo da variação diatópica dos sinais foi informado de acordo com Capovilla et al. (2017) e Soares $(2013,2019)$.

5 Sinal utilizado por sinalizante surdo de Recife (PE), conforme relato oral de Soares (2019). 
p. 226), por exemplo, divide a "microestrutura de base" em duas partes: entrada + enunciado lexicográfico, assim como Escribano (2003), que também divide o verbete em duas partes, porém nomeia-as com outra nomenclatura: lema (também conhecido como entrada) e informações (acerca da unidade lemática).

O lema é a unidade lexical do verbete, na forma canônica6. Martínez (2009, p. 104) o considera como "a parte mais importante do verbete lexicográfico". A definição, também nomeada de significado, sentido ou acepção, é o resultado da análise semântica da unidade lexical e de seus usos pragmáticos. Conforme Werner (1982, p. 271), o objetivo da definição lexicográfica, em dicionários semasiológicos e monolíngues, é fornecer ao consulente uma "instrução que lhe permita usar ou interpretar corretamente os signos linguísticos segundo seu papel de emissor linguístico, receptor e tradutor".

Além dessas duas unidades, Wiegand (1988 apud WELKER, 2004) mencionou o termo "cabeça do verbete" para denominar a parte que contém as informações (variantes ortográficas, a pronúncia, indicação da classe gramatical, da etimologia e das marcas de uso, dentre outros) anteriores à definição. Diferente da cabeça do verbete, as acepções (contidas no enunciado lexicográfico) são numeradas e recebem autonomia, possuem as suas próprias marcas de usos, abonações, sinônimos etc..

Sobre o tratamento dos homógrafos no dicionário especial, na obra lexicográfica Um significado só é pouco: Dicionário de Formas Homônimas do Português Contemporâneo do Brasil (DFH-PCB), de Zavaglia (2010), assim como no DCP (dicionário geral), o critério utilizado para distinção das formas homônimas foi o semântico, em detrimento do etimológico. Na microestrutura do $D F H-P C B$, ao invés de repetir o lema para cada significado diferente, como é de costume em dicionários gerais, Zavaglia (2010) eliminou a redundância e registrou o lema homônimo uma única vez; e, dele, desmembrou os significados próprios de cada um.

Para demarcar as fronteiras entre as variantes de um mesmo lema homógrafo (equivalente a lexias diferentes), foram utilizados números alceados. No verbete, pena, por exemplo, o lema principal e os blocos numerados equivalem a significados distintos. Ao todo, distinguiram-se três lexias com significados diferentes para o homógrafo pena.

Aautora (2010, p. VII) explicou que, no verbete, para cada variantehá, "além da sua definição, a sua ilustração contextual e/ou abonação". Ademais, para cada lema, há o gênero, a classificação gramatical, a(s) acepção(ões), variando entre uma ou mais acepções, e a abonação, com a sigla do corpus ao qual foi extraída. Além dessas informações, outras também podem ser incluídas, a depender do lema.

60 lema, em sua forma canônica, é resultante do processo de lematização da unidade lexical. Na forma canônica, o lema, em geral, é monomorfêmico, ou seja, é constituído pela palavra-entrada numa só forma. Ver Carballo, La Microestructura del dicionário (GERRA, 2003). 
No modelo do verbete apresentado pela lexicógrafa (ZAVAGLIA, 2010), a distinção entre som fechado ou aberto e a remissão a outro verbete são informações complementares que podem ser facilmente identificadas com o recurso de marcas de uso. Esse recurso serve, simplificadamente, segundo Fajardo (1996-1997), para facilitar a leitura e evitar ambiguidades.

No DCP, Biderman (1992) apresenta três entradas para a forma homônima pena. Cada unidade homógrafa tem uma entrada própria e carrega, no verbete, informações sobre a divisão silábica: a sílaba tônica, as formas gramaticais (plural, adjetivo, outros) esemânticas (sinônimos, antônimos), com sigla para remissão às demais entradas homônimas. 0 $D F H-P C B$ se destaca dentre esse e outros modelos porque não é um dicionário geral, mas especial. Diferentemente das obras mais tradicionais, ele dicionariza a homografia de uma forma simples e direta, e, acima de tudo, oferece uma solução ao problema do registro da homonímia quando fornece uma obra exclusivamente dedicada a esse tipo de lexia, muitas vezes esquecida nos dicionários gerais, por motivos de economia.

Nos dicionários gerais de Libras, as unidades lexicais homônimas não receberam destaque para esta informação ou muitas deixaram de ser contempladas na macroestrutura. No Novo Deit-Libras (2012), por exemplo, apenas o item lexical polissêmico recebeu registro sistemático, no interior da microestrutura e foi mencionado nos capítulos introdutórios, referentes à apresentação da obra (LEÔNCIO, 2018). Logo, considerando tais anotações, o dicionário especial pode vir a constituir-se como uma solução para o registro da homonímia da Libras, já que as informações visuais (sistema de busca, escrita de sinais, outros) do dicionário de LS, por si só, já avolumam, em grande medida, a macro e microestrutura de dicionários gerais.

\section{Procedimentos metodológicos}

Considerando o fato de que a libras não possui um largo banco de registros, capaz de fornecer a etimologia dos sinais, e que, como disse Correia (1998), apesar de ser um critério relevante, nem sempre a etimologia é suficiente, assumimos a posição teórica do DEA e do DEUM, a mesma adotada por Biderman (1984) e Zavaglia (2012), e optamos pelo uso do critério semântico para identificação de sinais homônimos.

Além disso, como não há consenso na LS sobre o código escrito da língua, havendo apenas algumas tentativas de representação para descrição linguística, como o Sistema de notação de Bébian (1789-1838), Stokoe (1919-2000) e Paul Jouison (1948-1991), o Sistema Brasileiro de Escrita da Língua de Sinais (ELIS), de Mariângela Estelita (1997), e o sistema SignWriting, desenvolvido para o uso cotidiano dos falantes, esta pesquisa não explorou a unidade lexical homônima em sua dimensão escrita, mas sim visual. 
Nesta pesquisa, a unidade lexical valorizada foi a lexia simples homônima, recolhida nas obras lexicográficas de referência do país, como o DV-Libras (2005), Deit-Libras (2001) e o DLSB (2017). O modelo do verbete é exemplificado por meio de cinco grupos de significantes homônimos (com dois a três significados), equivalentes ao total de treze lexias. O recorte sincrônico adotado foi o orientado por Biderman (1984), equivalente ao espaço de uma geração, ou seja, trinta anos. Após a recolha e identificação das unidades homonímias por meio da análise sêmica (investiga o sema numa dimensão sincrônica), todos os sinais foram inventariados, numerados com base na Tabela de CM da libras, disponível no DV-Libras, versão 2.0 (FELIPE; LIRA, 2005).

Ao todo, a metodologia foi desenvolvida em duas etapas, cada uma com suas respectivas fases. A primeira etapa foi composta por três fases, quais sejam: 1. Decisões introdutórias (público, tipo de lexia e tipologia lexicográfica); 2. Coleta do corpus em dicionários (DVLibras, Deit-Libras, DSLB), seguida do registro e catalogação dos sinais; e 3. Análise sêmica das homonímias coletadas nos corpora. Já a segunda etapa, propriamente lexicográfica, foi dividida em duas fases, a saber: 1. Composição do verbete: pesquisa e elaboração das informações lexicais e semântico-pragmáticas das entradas, definição das marcas de uso, referentes gráficos, ilustração dos sinais e formatos das mãos; e 2. Aplicação do repertório e dados ao modelo proposto pela pesquisa.

\section{Análise e resultados}

A microestrutura de base do modelo da pesquisa adotou a seguinte estrutura: entrada + equivalente em escrita de sinais + enunciado lexicográfico. A entrada definida foi o próprio sinal, elaborado no Adobe Illustrator em forma de desenho ${ }^{7}$. Essa escolha foi uma tentativa de reverter um problema histórico e universal de quase a totalidade dos dicionários de LS impressos, ou seja, a indexação pela ordem alfabética da língua escrita do país de publicação (DUDUCHI; CAPOVILLA, 2006).

Para registrar os sinais como entrada e gerar o sistema de indexação, antes foi preciso analisar, ordenar e identificar as Configurações de Mãos (doravante CMs) do corpus da pesquisa com base no "configureto" (sistema de ordenamento paramétrico das CMs), proposto por Faria-do-Nascimento (2009). Considerando a quantidade de alofones na tabela dessa autora, optamos por aplicar esse sistema de ordenação ao inventário 64 CM, de Felipe e Lira (2005).

A ordenação das CMs, com base nesse sistema, foi imprescindível para a classificação das entradas e ordenação dos lemas. As entradas foram pensadas para serem ordenadas

7 A ilustração da entrada em forma de desenho é uma possibilidade, dentre outras formas. Ela pode ser revista e alterada, futuramente, mediante a avaliação e indicação do público-alvo da proposta do verbete do dicionário. 
por agrupamentos (ver Figura 5), tanto na macro como na microestrutura. Esse tipo de arranjo, fornecido por Wiegand (1983 apud WELKER, 2004), organiza-se por blocos. Dentro de cada bloco ou nicho, como Welker (2004) prefere chamar, colocam-se os verbetes relacionados à CM e à Locação (doravante L), organizados em ordem paramétrica.

Para ordenar as subentradas, também foi necessário adotar um padrão sistemático de ordenação paramétrica. Nesse momento, a CM funcionou com o principal elemento regulador e a $L$ como o segundo. Vejamos:

Figura 6. Hierarquização dos verbetes

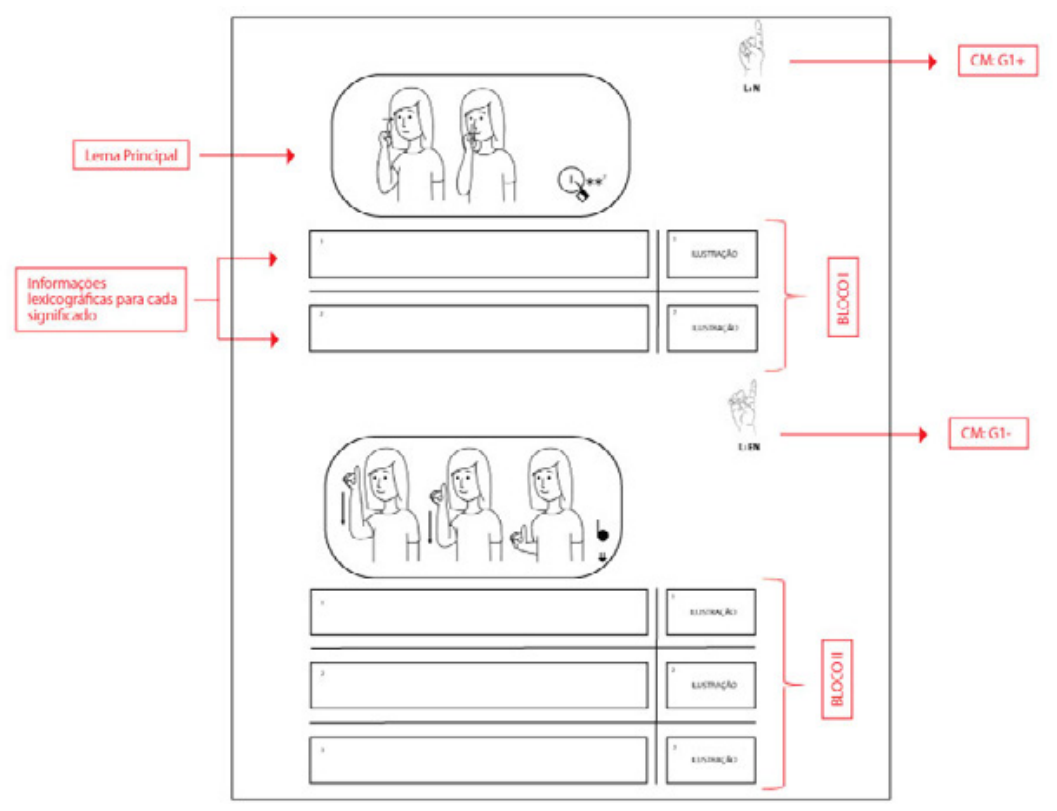

Fonte: Elaboração própria

Como mostra a imagem, as entradas sequenciadas pertencem ao mesmo grupo de CM. Nesses casos, a ordenação das entradas se guiou pelo critério de abertura e fechamento (da mais fechada para a mais aberta) e semelhança entre as CMs. Além disso, considerando que o sinal pode ser feito com uma ou duas mãos, em diferentes situações (duas mãos iguais, duas mãos diferentes, formato inicial e final iguais, formato inicial e final diferentes), optamos por ordenar tais variações de acordo com a distribuição proposta por Faria-do-Nascimento (2009).

Para o sistema de ordenação paramétrica pela L (locação), como segundo filtro de buscas, adotamos o modelo de classificação de Liddell \& Johnson (1989) (doravante L\&J), que divide o corpo em áreas e subáreas identificadas por siglas com pontos ilustrados no corpo, como se fosse uma espécie de mapa de Locações. Para proceder com a adaptação 
desse mapa para a Libras, tomamos como base os quadros de locações do corpo e da mão passiva da Libras (não contemplada no quadro original de L\&J (1989)) de Xavier (2006) e Faria-do-Nascimento (2009). Os sinais executados no espaço neutro, ou seja, distante ou sem tocar em uma região do corpo, foram apenas identificados pela sigla EN e ordenados do mais próximo ao mais afastado do corpo, com o intuito de simplificar e diminuir a quantidade de siglas.

Para ordenar as LS em um continuum e ampliar o escopo de Locações, não previstas por Xavier (2006), adotamos a proposta de Faria-do-Nascimento (2009). Nessa proposta, a autora propõe que a ordem ocorra no sentido longitudinal do corpo: de trás para frente e de cima para baixo. No sentido latitudinal do ponto mais próximo do corpo ao mais distante do corpo (do ponto mais central para o ponto mais periférico, seguindo a ordem - mais central, direita e esquerda (FARIA-DO-NASCIMENTO, 2009).

A sequência de Locações/Pontos de Articulação foi ordenada como consta no Quadro 1. Vejamos:

Quadro 1. Ordenação dos Pontos de Articulação

topo da cabeça $>$ posterior da cabeça $>$ nuca $>$ testa $>$ lado da testa $>$ sobrancelha $>$ olho $>$ nariz $>$ bochecha $>$ orelha $>$ boca $>$ dente $>$ língua $>$ lábio $>$ maxilar $>$ queixo $>$ pescoço (atrás) $>$ ombro > costas (parte alta) > braço (parte superior externo) > cotovelo > antebraço interno $>$ pulso (externo) > mão dorso > dedos (externo) > braço (parte superior interna) > antebraço interno $>$ pulso $($ interno $)>$ dedos $($ interno $)>$ mão $($ palma $)>$ tronco $>$ costas $($ parte baixa $)>$ peito > esterno > abdômen > cintura > região pélvica > quadril > coxa > nádegas

Fonte: Elaboração própria a partir de Faria-do-Nascimento (2009)

Assim como no dicionário $D F H-P C B$, optou-se por registrar uma entrada principal e dela desmembrar blocos de informações lexicográficas para cada significado diferente. No modelo apresentado a seguir, as formas homônimas DIREITO, DIRETOR e DEFICIÊNCIA ilustram essa estrutura: 
Figura 7. Base estrutural do verbete

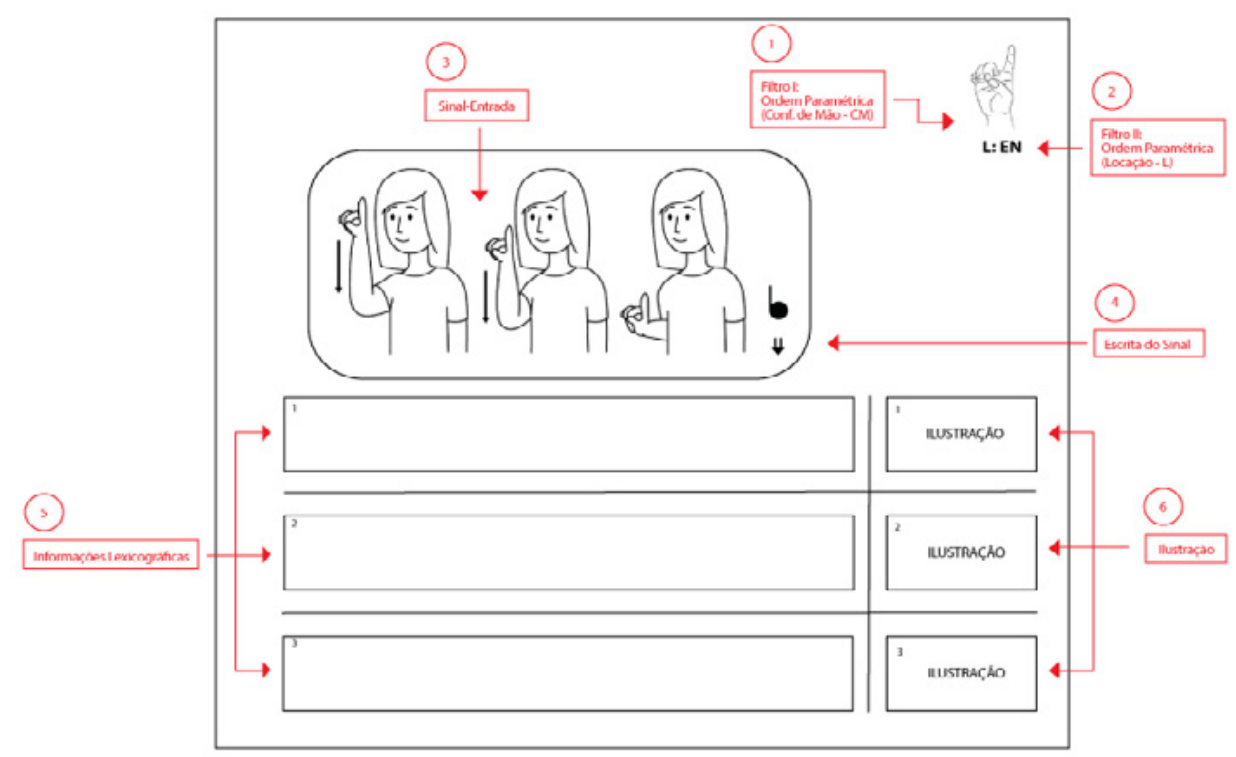

Fonte: Elaboração própria

No esquema gráfico da microestrutura acima, cada elemento contido no protótipo do verbete foi numerado para orientar as explicações conduzidas nesta seção. Desse modo, os quadros foram assim identificados: $\mathbf{n}$. 1: sistema de busca e ordenação por CM; $\mathbf{n}$. 2: sistema de busca por locação; n. 3: sinal-entrada; n. 4: escrita de sinal; n. 5: informações sobre o lema; n. 6: ilustração da definição.

O balão explicativo $\mathbf{n}$. 1 corresponde ao sistema de busca e ordenação das entradas na macroestrutura. No modelo, a ordenação das entradas se dá, primeiro, por CM (na macroestrutura) e, depois, por L (na microestrutura). Elas foram dispostas, na macroestrutura, verticalmente para facilitar esse continuum. Para que isso fosse possível, a $L$ foi ordenada a partir das grandes áreas: cabeça, tronco, braço, mão, perna, tomando por referência as seguintes sequências: de trás para frente, de cima para baixo, do ponto mais próximo (PROXIMAL) ao mais distante do corpo (DISTAL), do mais central ao mais periférico (direita e esquerda), do ponto próximo (PROXIMAL) ao médio (MEDIAL) e do médio (MEDIAL) ao mais distante do corpo (DISTAL). Voltando ao Quadro 1, é possível rever a ilustração desse sistema de ordenação.

A entrada do verbete (Figura 7) ganhou local de destaque e a ela foi adicionada, lateralmente (lado direito), a escrita do sinal. Essas duas unidades referem-se a todas as subentradas, por isso, elas aparecem em posição central enquanto os blocos de informações, como periféricos (ver Figura 5). O balão n. 5 corresponde ao local dos blocos de informações da entrada principal. 
Por último, foram incluídas ilustrações ${ }^{8}$ para cada um dos conceitos diferentes com a pretensão de ajudar o consulente a compreender e diferenciar os significados. Fariado-Nascimento (2009, p. 214) explica que obras lexicográficas para falantes da Libras "precisam 'abusar', de certa maneira, dos recursos visuais, sem, no entanto, poluir os repertórios com excessos desse tipo de estímulo". Em outras palavras, os recursos visuais favorecem o dicionário voltado para o público surdo, na medida em que são funcionais e estão em acordo com o conjunto de informações do verbete.

Para apresentar o modelo de verbete formulado nesta pesquisa, optou-se por separar a microestrutura em microestrutura abstrata e concreta. Essa distinção foi empregada por Welker (2004) e por Wiegand (1989 apud FARIAS, 2011) para distinguir a estrutura padrão (abstrata), uma espécie de molde de verbete sobre o qual se deve aplicar os dados concretos de cada lema, individual, respeitando uma ordem canônica.

Figura 8. Microestrutura abstrata

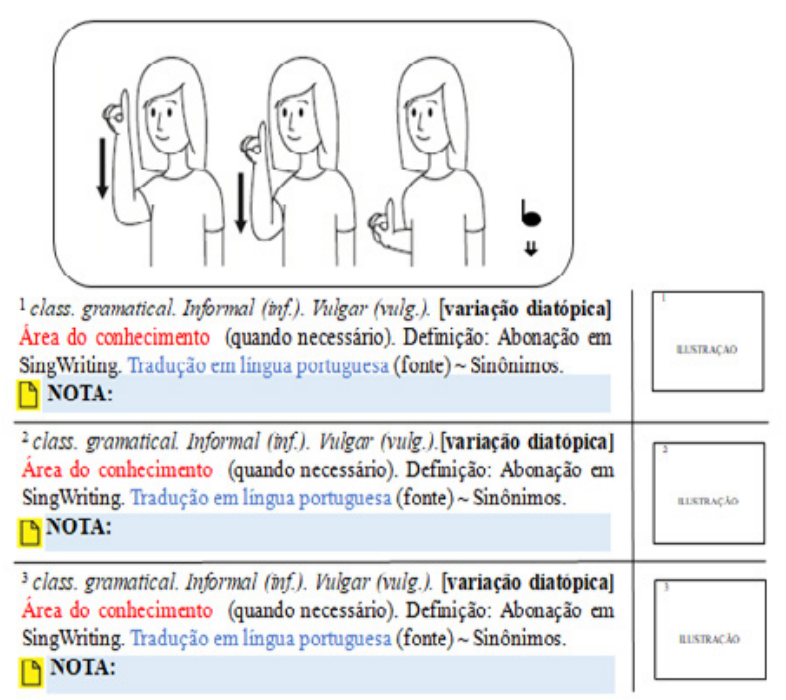

Fonte: Elaboração própria

A microestrutura abstrata ilustrada acima contém informações de forma, definição, exemplo de uso, sinônimo e também de certas nuances e curiosidades sobre a unidade homônima. As informações de forma correspondem, segundo Welker (2004, p. 111), às variantes "ortográficas, à pronúncia, à categoria gramatical, às informações flexionais

8 As ilustrações utilizadas não correspondem às imagens finais do verbete, elas foram inseridas apenas para ilustrar o modelo. Nossa intenção é, futuramente, no doutorado, aprofundar as discussões sobre esse recurso e apresentar as ilustrações definitivas e adequadas à faixa etária do público-alvo da produção. 
e/ou sintáticas, à etimologia, às marcas de uso", constantes na cabeça do verbete. Na proposta, as informações desse grupo englobam o lema (sinal ilustrado), seu equivalente em escrita de sinais, a classe gramatical e as marcas de uso (diatópica, diafásica, diastrática, diatécnica). O comentário pós cabeça do verbete, por sua vez, está composto pela definição, exemplo (com sua respectiva tradução para a LP) e o(s) sinônimo(s).

A entrada, o próprio sinal, foi ilustrada conforme as orientações lexicográficas de Fariado-Nascimento (2009) que propõe que os desenhos sigam os mesmos princípios das fotografias, obedecendo regras de articulação, enquadramento, lateralidade, número de mãos e pontos de articulação.

A categoria gramatical, abreviada e grafada em itálico, vem na cabeça do verbete, logo após o número alceado. Essa informação ajuda a diferenciar a classe gramatical, indicando o tipo de homonímia que se está diante (lexical ou semântica). Destacamos que o gênero gramatical não foi inserido junto à classificação gramatical porque, na Libras, os sinais recebem esta flexão mediante o contexto de uso.

A escrita de sinais, enquanto equivalente da entrada, foi uma decisão importante para a proposta, pois ela fornece o sinal representado em traços simultâneos, reproduzindo suas relações e propriedades internas, com exceção das Expressões não Manuais (ENMs). Atualmente, o SignWriting está entre os sistemas de escrita mais utilizados no mundo, além disso, "as crianças surdas que se comunicam por sinais precisam poder representar pela escrita a fala delas que é visiográfica" (STUMPF, 2005, p. 44). Por isso, optou-se por oferecer exemplos/contextualização em escrita de sinais, exatamente porque a sintaxe da LP oferece maiores dificuldades para o surdo do que a sintaxe da LS (STUMPF, 2005), de todo modo, a compreensão da escrita não é um pré-requisito para a leitura do verbete, uma vez que o usuário previsto deve ser bilíngue.

As marcas de uso, muito frequentes em dicionários monolíngues (pouco menos frequente nos bilíngues) das línguas orais-auditivas e ainda pouco utilizadas nos dicionários de libras, receberam atenção especial na nossa proposta. Como o objetivo era fornecer o maior número de informações sobre o uso das entradas, foram valorizadas as variações diatópicas (origem regional, nacional), diafásicas (informal), diastráticas (vulgar) e diatécnicas (área do conhecimento).

Cada uma dessas variações foi destacada e padronizada com recursos gráficos específicos, visando inibir conflitos na leitura. A variação diatópica, por exemplo, foi grafada em negrito, dentro de colchetes com a sigla do estado abreviado. Já as variações diafásica e diastrática, inseridas logo após a classificação gramatical, receberam o recurso de destaque em itálico, para os termos abreviados informal (inf.) e vulgar (vulg.). A última marca de uso empregada foi a diatécnica. Ela foi destacada na cor vermelha, de forma abreviada. Sabendo que são inúmeros os tecnoletos e que um dicionário especial 
não tem necessariamente essa função, foram definidas como marcas técnicas os seguintes campos: botânico (bot.), economia (econ.) e direito (dir.). Para as palavras que fazem parte da "linguagem comum ou geral", não julgamos necessário apresentar tais marcas.

A definição lexicográfica, considerada por alguns (MARTíNEZ DE SOUSA, 2009) como a parte principal do verbete, foi formulada a partir de obras lexicográficas de referência e materiais de cursos de libras do país. Ela foi colocada logo após as marcas de uso, na cor azul para contrastar as estruturas sintáticas da LP e LS. Após a definição, separado pelo símbolo ( : ), foi inserido o exemplo (em escrita de sinais), seguido da transcrição para a LP e a fonte (entre parênteses e abreviada) de onde foi retirado. Após a fonte do exemplo de uso, foi(foram) inserido(s) o(s) sinônimo(s), precedido(s) pelo acento til ( ).

Ao final do verbete, o segmento destinado à(s) nota(s) explicativa(s) foi adotado com o objetivo de fornecer informações complementares sobre o lema, tais como: variação fonológica, apontar o uso do morfema lexical homem/mulher, classificadores (unidade fonológica que compõe o sinal), advérbios, intensificadores ou, simplesmente, para chamar atenção para nuances do significado. As notas aparecem em fundo azul, como pós-comentário, com fonte menor (tam. 10), precedidas pelo símbolo D e a palavra NOTA (em caixa alta e em negrito, seguida de dois pontos). Se a nota for referente a alguma acepção específica, deve vir logo após o exemplo.

Por fim, a microestrutura concreta, organizada a partir da microestrutura abstrata, foi elaborada para ilustrar o modelo final do verbete desta pesquisa. As unidades lexicais MÃE/BISCOITO; DIREITO/DIRETOR/DEFICIENTE; SÁBADO/LARANJA; MATEMÁTICA/ MINUTO/MARANHÃO; SENTIR/JEITO/BAHIA foram empregadas para exemplificar o modelo do verbete descrito acima e aplicar o "Programa Constante de Informações", aludido por Farias (2011). Todos os verbetes seguiram o mesmo padrão. Alguns diferiram por características particulares. 
Figura 9. Microestrutura concreta - MÃE/BISCOITO9

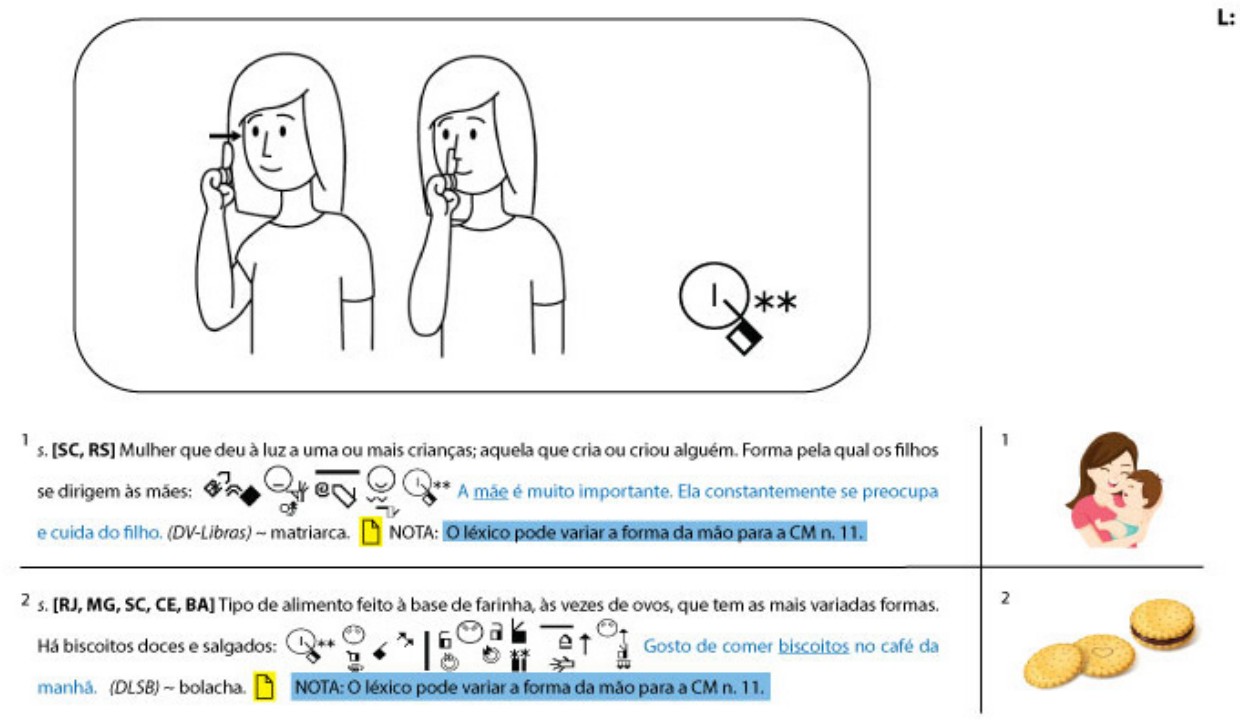

Fonte: Elaboração própria

Os blocos de significados, no exemplo acima, referem-se às unidades homônimas MÃE/ BISCOITO. Para cada significado do lema, foram apresentados um ou mais conceitos, numerados e com informações particulares. Optamos por definições lexicográficas curtas, objetivas e transparentes, e, para cada acepção, fornecemos a contextualização de uso com frases. Quando havia mais de uma acepção, em consonância com Hernández (1991 apud DURÃO et al., 2013), cada uma era numerada, separada por ponto e vírgula e com suas próprias marcas e exemplos, como vemos no exemplo da Figura 6. Os exemplos, por seu valor elucidativo, receberam um tratamento especial no modelo do verbete e foram escritos em SignWriting, uma escrita não alfabética, mas ideográfıca, artefato simbólico da cultura surda. Como a língua de referência é a própria LS, procuramos trazê-la logo após a definição, seguida da transcrição em LP (para aqueles que não conhecem ou utilizam a escrita), com o nome da lexia em LP sublinhado para destacar a sua aplicação na frase.

9 Referências das imagens: Disponível em: https://www.freepik.com/free-photos-vectors/ background. Background vector created by freepik - Disponível em: www.freepik.com. Acesso em: 10 jul. 2018. href="https://www.freepik.com/free-photos-vectors/background. Background vector created by vectorpocket - www.freepik.com. Acesso em: 10 jul. 2018. 
Ainda na microestrutura do modelo da pesquisa, os sinônimos (Sin.) também foram utilizados como informações de comentário semântico do "Programa Constante de Informações" (doravante PCI). Como se sabe, nos casos em que essa informação não aparece no verbete, deduz-se, se o lexicógrafo segue rigorosamente o PCl, que a LS não dispõe de sinônimo para as unidades léxicas em questão e se está diante de um "grau zero de informação" (FARIAS, 2011), como ocorre no caso do verbete abaixo, em que dos três significados diferentes, dois possuem sinônimos.

Figura 10. Microestrutura concreta - DIREITO/DIRETOR/DEFICIENTE10

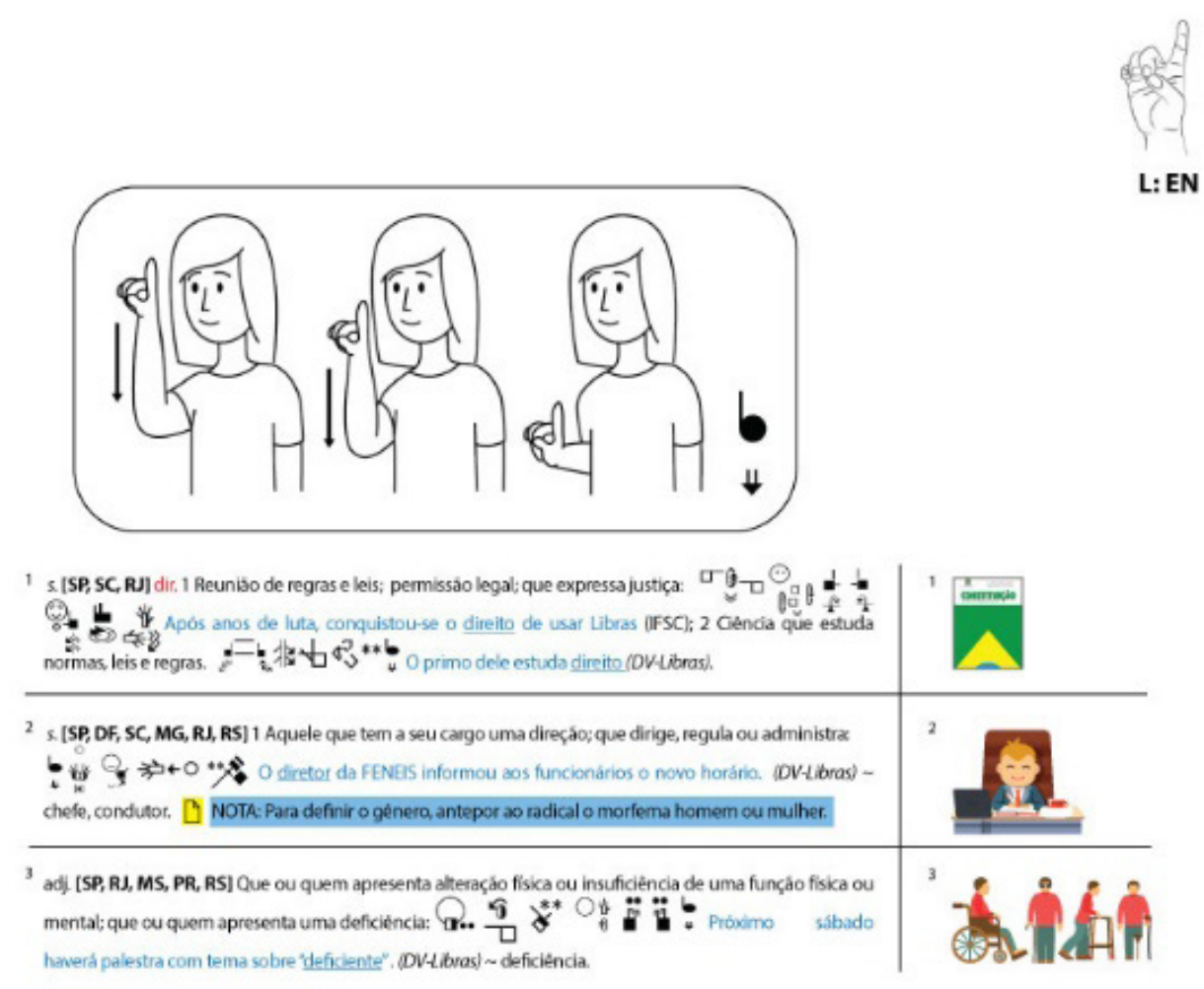

Fonte: Elaboração própria

Quanto à estrutura de organização da microestrutura, Wiegand (1989 apud FARIAS, 2011) a distingue em dois tipos: a microestrutura ampliada [erweiterte Mikrostruktur] e a microestrutura composta [zusammengesetzte Mikrostruktur]. No verbete desta pesquisa, optamos por trabalhar com a microestrutura ampliada. Ela abriga uma estrutura marginal

10 Referências das imagens: Disponível em: https://pt.wikipedia.org/wiki/Ficheiro:CF88_Livro_ EC91_2016.png. Acesso em: 10 mar. 2019. Disponível em: https://www.freepik.com/free-photosvectors/business. Business vector created by iconicbestiary - www.freepik.com. Acesso em: 10 mar. 2019. Disponível em: https://www.freepik.com/free-photos-vectors/business. Business vector created by macrovector - www.freepik.com. Acesso em: 10 mar. 2019. 
à direita, logo após o comentário semântico da estrutura base, e serve para abrigar as informações extraordinárias, não previstas no PCI. Um exemplo na pesquisa foi o verbete da Figura 5. Nesse verbete, foi expedido um "comentário de forma" referente ao significado da unidade DIRETOR, com o intuito de orientar o uso do gênero junto ao radical da lexia.

Outro artifício escolhido, com a função de ampliar as informações sobre o(s) significado(s), foram as ilustrações. Elas foram introduzidas para além de um mecanismo complementar e/ou alternativo de elucidação do(s) significado(s). Para dicionários de LS, em que o principal consulente (o surdo) interage com o mundo, principalmente, por experiências visuais, o recurso ilustrativo parece receber uma posição de destaque ao invés de um status secundário, como é comum nos dicionários da línguas orais-auditivas (FARIAS, 2011).

\section{Considerações finais}

Baseados nos resultados desta pesquisa, verificou-se que, dentre as decisões tomadas, a arquitetura com pós-comentário, baseada em Wiegand (1989 apud FARIAS, 2011), muito comum nos dicionários de línguas orais-auditivas, possibilitou ampliar as informações da homonímia para além das já previstas no $\mathrm{PCl}$, fornecendo ao usuário informações e detalhes não encontrados nos dicionários de LS, em geral. Este foi um dos pontos chave deste estudo, documentar a homonímia da libras, fornecer informações para a compreensão dos seus usos e significado e, ainda, propor uma solução para seu registro, em função do pouco espaço para arrolamento em dicionários gerais e da incompatibilidade com os objetivos do dicionário bilíngue.

A inserção do sinal com sua respectiva escrita na entrada do verbete, os exemplos de uso (retirados de dicionários de Libras (DV- Libras e o DLSB), Língua Portuguesa (DCP) e apostila (CEFET-SC) de cursos de Libras) em SignWriting e, com tradução em LP, o sistema de ordenação e busca da nomenclatura baseados na estrutura fonológica da Libras, e os diversos recursos tipográficos com símbolos e cores, foram algumas das tentativas de colocar a LS e o surdo ou usuário bilíngue como centro de todo o trabalho lexicográfico.

No decurso do trabalho lexicográfico, verificamos que as decisões ultrapassaram um mero fazer lexicográfico, demandando conhecimentos e habilidades de uso formal, semântico e pragmático da Libras. A constituição de grupos heterogêneos com lexicólogos, lexicógrafos e pesquisadores da LS, incluindo, essencialmente, usuários surdos e ouvintes bilíngues, pode fortalecer o trabalho e descentralizar escolhas, colocando a LS como alvo de todo o projeto lexicográfico. 
Em virtude do pouco tempo da pesquisa, não foi possível aplicar uma sondagem junto ao público-alvo para validar as ilustrações, bem como o próprio modelo do verbete. Cientes da importância dessa etapa do trabalho lexicográfico e da sua complexidade, nos propomos, nesta pesquisa, a desenvolver apenas o protótipo, reservando a sua aplicação a testes e sondagens posteriores, durante o doutorado, no qual disporemos de tempo e condições ideais para arquitetar, aplicar, analisar e empregar os dados dos testes e sondagens junto ao público-alvo definido, a priori, para o verbete.

\section{REFERÊNCIAS}

BALDINGER, K. Teoria semántica: hacia una semántica moderna. Madrid: Ed. Alcalá, 1970.

BARBOSA, M. A. Réflexions sémantiques sur l'article dans l'oeuvre lexicographique. Meta $X L I$, n. 2, p. 265-274, 1996.

BIDERMAN, M. T. C. Dicionário Contemporâneo de Português. Petrópolis: Vozes, 1992.

BIDERMAN, M. T. C. A ciência da Lexicografia. Alfa, São Paulo, n. 28, p. 1-26, 1984.

BIDERMAN, M. T. C. Teoria linguística: linguística quantitativa e computacional. Rio de Janeiro: Livros Técnicos e Científicos, 1978.

CANÇADO, M. Manual de semântica: noções básicas e exercícios. Belo Horizonte: Editora UFMG, 2008.

CAPOVILLA, F. C.; RAPHAEL, W. D. Dicionário Enciclopédico Ilustrado Trilíngue: Língua de Sinais Brasileira. v. 1. São Paulo: EDUSP, 2001a.

CAPOVILLA, F. C.; RAPHAEL, W. D. Dicionário Enciclopédico Ilustrado Trilíngue: Língua de Sinais Brasileira. v. 2. São Paulo: EDUSP, $2001 b$.

CAPOVILLA, F. C.; RAPHAEL, W. D.; MAURÍCIO, A. C. Novo Deit-Libras: Dicionário enciclopédico ilustrado trilíngue da Língua de Sinais Brasileira (Libras). v. 1. 2. ed. São Paulo: EDUSP, 2012a.

CAPOVILLA, F. C.; RAPHAEL, W. D.; MAURÍCIO, A. C. Novo Deit-Libras: Dicionário enciclopédico ilustrado trilíngue da Língua de Sinais Brasileira (Libras). v. 2. 2. ed. São Paulo: EDUSP, 2012b. 
CAPOVILLA, F. C. et al. Dicionário da Língua de Sinais do Brasil: a Libras em suas mãos. São Paulo: EDUSP, 2017.

CARBALLO, M. A. C. La macroestructura del Dicionario. In: GUERRA, A. M. M. Lexicografía española. Espana: Ariel, 2003.

CORREIA, M. Homonímia e polissemia - contributos para a delimitação dos conceitos. Palavras, Lisboa: Associação dos Professores de Português, n. 19, p. 57-75, 1998.

DUDUCHI, M.; CAPOVILLA, F. C. BuscaSigno: a construção de uma interface computacional para acesso ao léxico da Língua de Sinais Brasileira. VI Simpósio sobre Fatores Humanos em sistemas computacionais - integrando pessoas, comunidades e áreas. Natal: UFRN, 2006.

DURÃO, A. B. de A. B. et al. Dicionário de Falsos Amigos Português - Espanhol (DiFAPE). v. 1. Florianópolis: Editora Insular, 2013.

ESCRIBANO, C. G. La microestructura del dicionário: las informaciones lexicográficas. In: GERRA, A. M. M. (org.). Lexicografía Española. Barcelona: Editora Ariel S. A., 2003.

FARIAS, V. S. Considerações preliminares sobre o pós-comentário na microestrutura de dicionários semasiológicos. REVEL, v. 9, n. 17, p. 109-139, 2011.

FARIA-DO-NASCIMENTO, S. P. de. Representações Lexicais da Língua de Sinais Brasileira: uma proposta lexicográfica. 2009. Tese (Doutorado em Linguística, Português e Línguas clássicas) - Instituto de Letras, Universidade Federal de Brasília, Brasília, 2009.

FARIA-DO-NASCIMENTO, S. P. Introdução à gramática da Libras. In: FERREIRA-BRITO, L. (org.). Educação Especial Língua Brasileira de Sinais. v. 3. Brasília: SEESP, 1997.

FARIA-DO-NASCIMENTO, S. P. A relação sintático-semântica dos verbos na língua brasileira de sinais (LIBRAS). 1998. Tese (Doutorado em Linguística e Filologia) - Instituto de Letras, Universidade Federal do Rio de Janeiro, Rio de Janeiro, 1998. Volumes I e II. Disponível em: https://bit.ly/2XzvAby. Acesso em: 3 jan. 2018.

FELIPE, T. A. Banco de dados para as línguas de sinais e seus sistemas de transcrição. In: BAALBAKI, A.; CALDAS, B. (org.). Instrumentos linguísticos: usos e atualizações. Araruama: Editora Carolina, 2014. p. 155-188. 
FELIPE, T. A. A relação sintático-semântica dos verbos na Língua Brasileira de Sinais (LIBRAS). 1998. Tese (Doutorado em Linguística) - Universidade Federal do Rio de Janeiro, Rio de Janeiro, 1998. v. I e II.

FELIPE, T. A. Introdução à Gramática da LIBRAS. Educação Especial - Língua Brasileira de Sinais. Brasília, MEC/SEESP: Série Atualidades Pedagógicas 4, 1997. p. 81-123.

FELIPE, T. A. O signo gestual-visual e a sua estrutura frasal na língua de sinais dos centros urbanos brasileiros. 1988. Dissertação (Mestrado em Linguística) - Centro de Artes e Comunicação, Universidade Federal de Pernambuco, Recife, 1988.

FELIPE, T. A.; LIRA, G. A. Dicionário Virtual de Língua Brasileira de Sinais. cd-rom/online. Versão 2.0. Rio de Janeiro: INES, 2005. Disponível em: http://www.ines.gov.br/dicionariode-libras/main_site/libras.htm. Acesso em: 03 jan. 2018.

HAENSCH, G. et al. La lexicografía. Madrid: Editorial Gredos, 1982.

LEÔNCIO, E. L. Análise comparativa da macro e microestrutura de dicionários de Libras. Anais do I fórum internacional sobre produção de glossários e dicionários em língua de sinais. Niterói: Universidade Federal Fluminense, 2018.

LIDDELL, S. K.; JOHNSON, R. E. American sign language: the phonological base. Sign Language Studies. v. 64, fall 1998.

MARTÍNEZ DE SOUSA, J. Manual básico de lexicografia. España: Ediciones Trea, S. L., 2009.

MARTÍNEZ DE SOUSA, J. Dicionário de lexicografia prática. Barcelona: Bibliograf, 1995.

MARTINS, T. A. Um estudo descritivo sobre as manifestações da ambiguidade lexical em libras. 2013. Dissertação (Mestrado em Letras) - Universidade do Oeste do Paraná, Cascavel, 2013.

QUADROS, R. M.; KARNOPP, L. B. Língua de sinais brasileira: estudos linguísticos. Porto Alegre: Artmed, 2004.

REY-DEBOVE, J. Léxico e dicionário. Tradução Clóvis Barleta de Morais. Alfa, São Paulo, 28 (supl.), p. 45-69, 1984. 
SOARES, C. P. Sinal utilizado por sinalizante surdo de Recife (PE): ADOTAR (CE, RJ)/ LUCRAR. Relato oral, Florianópolis - SC, 2019.

SOARES, C. P. Demonstração da ambiguidade de itens lexicais na LSB: um estudo sincrônico de homonímia. 2013. Dissertação (Mestrado em Linguística, Português e Línguas Clássicas) - Instituto de Letras, Universidade de Brasília, Brasília, 2013.

STUMPF, M. R. Aprendizagem de escrita de língua de sinais pelo sistema SignWriting: línguas de sinais no papel e no computador. 2005. Tese (Doutorado em Informática na Educação) - Instituto de Letras, Universidade Federal do Rio Grande do Sul, Porto Alegre, 2005.

SUTTON, V. Lições sobre o SignWriting: um sistema de escrita para língua de sinais. Tradução Marianne Rossi Stumpf - Tradução Parcial e Adaptação do Inglês/ASL para Português LIBRAS do livro "Lessons in SignWriting", de Valerie Sutton, publicado originalmente pelo DAC - Deaf Action Committe for SignWriting. 2019 [1974]. Disponível em: https://bit.ly/2M8FZ80. Acesso em: 17 jan. 2019.

ULLMANN, S. Semântica: uma introdução à ciência do significado. Tradução J. A. Osório Mateus. Lisboa: Fundação Calouste Gulbenkian, 1964.

XAVIER, A. N. Descrição fonético-fonológica dos sinais da língua de sinais brasileira (Libras). 2006. Dissertação (Mestrado em Semiótica e Linguística Geral) - Faculdade de Filosofia, Letras e Ciências Humanas, Universidade de São Paulo, São Paulo, 2006.

ZAVAGLIA, C. Metodologia em ciências da linguagem: lexicografia. In: GONÇALVES, A. V.; GÓIS, M. L. de S. (org.). Ciências da linguagem: o fazer científico. 1. v. Campinas: Mercado de Letras, 2012.

ZAVAGLIA, C. Um significado só é pouco: dicionário de formas homônimas do português contemporâneo brasileiro. Rio de Janeiro: Editora Ciência Moderna Ltda., 2010.

WELKER, H. A. Dicionários: uma pequena introdução à lexicografia. 2. ed. Brasília: Thesaurus, 2004.

WERNER, R. La definición lexicográfica. In: HAENSCH, G. et al. La lexicografia. Madrid: Editorial Gredos, 1982. 